Chapman University

Chapman University Digital Commons

Psychology Faculty Articles and Research

Psychology

$12-2005$

\title{
Nonlinear Dynamics and Interpersonal Correlates of Verbal Turn-Taking Patterns in a Group Therapy Session
}

David Pincus

Chapman University, pincus@chapman.edu

Stephen J. Guastello

Marquette University

Follow this and additional works at: http://digitalcommons.chapman.edu/psychology_articles

Part of the Other Psychiatry and Psychology Commons, Other Psychology Commons, Psychoanalysis and Psychotherapy Commons, Social Psychology Commons, and the Social Psychology and Interaction Commons

\section{Recommended Citation}

Pincus, David, and Stephen J. Guastello. (2005)."Nonlinear dynamics and interpersonal correlates of verbal turn-taking patterns in a group therapy session." Small group research 36(6), 635-677. doi: 10.1177/1046496405280864

This Article is brought to you for free and open access by the Psychology at Chapman University Digital Commons. It has been accepted for inclusion in Psychology Faculty Articles and Research by an authorized administrator of Chapman University Digital Commons. For more information, please contactlaughtin@chapman.edu. 


\section{Nonlinear Dynamics and Interpersonal Correlates of Verbal Turn-Taking Patterns in a Group Therapy Session}

\section{Comments}

This is a pre-copy-editing, author-produced PDF of an article accepted for publication in Small Group Research, volume 36, issue 6, in 2005 following peer review. The definitive publisher-authenticated version is available online at DOI:10.1177/1046496405280864.

\section{Copyright}

The authors 
Running head: NONLINEAR DYNAMICS IN GROUP THERAPY

Nonlinear Dynamics and Interpersonal Correlates of Verbal Turn-taking Patterns in a Group Therapy Session

David Pincus, Psychology Department, Chapman University, Orange, CA

Stephen J. Guastello, Psychology Department, Marquette University, Milwaukee, WI

Revised and resubmitted 6/05

Correspondence should be addressed to:

David Pincus, Ph.D.,

Dept. Psychology, Chapman University

One University Drive

Orange, CA 92866

Tel: 714-744-7917. Fax: 714-997-6780 .E-mail: pincus@chapman.edu 


\begin{abstract}
Interpersonal processes and dynamics are ubiquitous topics in psychotherapy, yet they are difficult to study and have become theoretically fragmented across therapeutic sub-disciplines. The current study tested an integrative model of interpersonal dynamics in small groups using nonlinear dynamical systems theory. The conversation of one group therapy session (with six adolescent sex offenders) was analyzed using orbital decomposition, which allows for the identification of patterns in categorical time-series data. The results showed evidence of selforganizing social patterns, based on formal measures of turbulence (Lyapunov dimension), information novelty (Shannon's entropy), and complexity (fractal dimension). The degree of patterning in turn-taking was significantly correlated with measurements of control, closeness, and conflict among group members. Clinical implications and directions for future research are discussed.
\end{abstract}


Nonlinear Dynamics and Interpersonal Correlates of Verbal Turn-taking Patterns in Group Therapy

\section{Introduction}

The mysteries of interpersonal dynamics have interested researchers and practitioners since the beginning of the field of psychotherapy itself. The works of Freud (1905), Lewin (1951), Sullivan (1953), Yalom (1985), and the emergence of family systems theory (Nichols \& Schwartz, 1998) each represent notable historical landmarks of this interdisciplinary evolution, with numerous branches moving in various directions along the way. However, direct empirical testing of interpersonal processes themselves has been challenging (Bales, 1999; Hare, \& Davies, 1994), as has the integration of practice and research. Clinicians have tried to address momentby-moment processes, while researchers have relied too heavily upon linear experimental designs, self-report measures, and group averages, each of which may obscure a group's most interesting dynamics (Arrow, McGrath, \& Berdahl, 2000; Bales, 1999; Burlingame, Fuhrman, \& Drescher, 1984; Gottman, Murray, Swanson, Tyson, \& Swanson, 2002; Hare \& Davies, 1994). Through the use of nonlinear dynamical systems theory (NDS) and methodologies, the current study aimed to capture some of these interesting dynamics in a relatively direct and novel way. Two primary questions were addressed. First, what is the nature of repeating turn-taking patterns during a youth group therapy discussion? And second, what is the interpersonal meaning of these patterns? The first question involved measuring the degree of complexity and coherence present in the turn-taking patterns using indexes of turbulence, novelty, and complexity. To address the second question, these repeating patterns of turn-taking were examined for interpersonal meaning, the putative connection between pattern repetition and the relational qualities of conflict, closeness and control.

Interpersonal systems: From 5-R's to 3-C's

The idea that relational qualities contribute to group-level coherence (e.g., pattern repetition) comes from the 5-R model, which was designed as to be an empirically testable integrative clinical framework for conjoint therapies (i.e., group, marital, and family therapy; for 
a complete discussion and initial test of the model see Pincus, 2001). The underlying assumption of the model is that small group and family systems literatures contain many overlapping constructs regarding information exchange and the evolution of relationships over time. The model was derived through an integrative conceptual analysis of the various family systems theories that identified four broad targets in conjoint family treatment: rules, roles, relationships, realities and response-patterns. These aspects of family systems were proposed to be codetermining of one another over time through a process known as self-organization, which characterizes systems that regulate their own flows of information (Bak, 1996; Kauffman, 1995).

To gain access to a group's self-organizing and evolutionary properties, the 5-R model suggests that researchers or clinicians may focus on five highly interactive qualities of groups: responses, rules, roles, relationships, and realities - each of which is well researched across the interpersonal disciplines, but which can be redefined with respect to information flow. Responses are defined as patterns of verbal turn-taking behavior in a small group that may be directly observed as they unfold over time, allowing for the calculation of measures of entropy or complexity through sequential analyses. Rules that are guiding the discussion may then be inferred, which are formally defined as boundaries around sequences of responses - what may and man not be said. Roles are defined as boundaries unique to each particular group member, and relationships are defined as boundaries that emerge from role-constellations of multiple members (i.e., parent-child). At the largest scale a group's realities are defined as coherentstructures within information flows of the group as a whole that may that tend to be represented within the minds of group members as schema. As the name suggests, realities may guide member's perceptual processes and other judgments (e.g., Asch, 1956; Baldwin, 1995; Festinger, 1954; Yee, Santoro, Paul, \& Rosenbaum; 1996).

The model defines the regulation of information flow as the fundamental purpose of small groups, because this self-regulation is what gives the group the ability to stay in existence and evolve in response to internal and external information shifts. When people get together in groups, there is a pull to communicate, and the communication pulls. As group members 
regulate on another, coordination emerges, and patterning may be observed in verbal turn-taking. Hypothetically, these patterned flows underlie the coherent properties present in small groups rules, roles, and so on.

An initial empirical test of the 5-R model (Pincus, 2001) suggested that the turn-taking patterns within a clinical family discussion were indeed characteristic with the type of complex patterning observed in self-organizing systems across a variety of scientific disciplines. The study also included a qualitative post-hoc analysis relating the most highly recurring patterns to the roles and relationships among the family members. Two prior studies of non-familial groups found dovetailing evidence of self-organization in the form of patterned sequences of different types of speech (based on coding the content of verbal responses), without regard to turn-taking (Guastello, 2000; Guastello, Hyde, \& Odak, 1998). The current study aimed to extend these results to the group therapy context and to examine the putative connections among response patterns, roles, and relationships in a more rigorous manner than Pincus' (2001) study. While a great number of roles and relational constellations are possible in small groups - this initial test focused on conflict, closeness and control (3-C's).

Conflict, as it is defined here, is a process in which one group member expresses disagreement with another member, a dyadic definition. More broadly, conflict may be described by interpersonal and attitudinal distance (Bales, 1970), negative affect, and behavioral expression of hostility during interaction (Gottman, 2002). According to interpersonal circumplex models, (Kiesler, 1983; 1996; Leary, 1957), hostility is a mutual quality in relationships - and indeed expressed hostility has been found to be associated with rigid coordination in interaction patterns, most consistently in the marital literature (i.e., for a review see Gottman, 1999).

Closeness may be operationally defined as a dyadic process in which one group member expresses agreement with another member. It may be conceptualized as the positive end of the affiliation dimension from interpersonal circumplex models (Kiesler, 1996) or similarly the friendliness end of the friendly-unfriendly dimension from the independent yet overlapping small-group work of Bales (1999). Closeness may also be understood to be the dyadic building- 
blocks of group cohesion (Baron, Amazeen, \& Beek, 1994; Kaul \& Bednar, 1986). However it is understood - each of these approaches to closeness consider it to be a reciprocal process with expressed agreement and positive affect pulling for like responses from others.

Like conflict and closeness, control can be multifaceted and difficult to define operationally (Hollander \& Offermann, 1990). Control within the current study is defined as relative influence over the behavior of other members, or more specifically the relative use of control-related statements (e.g., commands or topic changes). Bales (1999) has found a number of connections between leadership and patterned responses in small-groups. For example, higher-ranking members of a group tend to speak more often, and lower ranking members tend to direct more utterances up the ladder of the control structure than vice-versa. As one moves up the ladder more utterances are addressed to the group as a whole, rather than a specific individual. Groffman and Owen (1983) provided a similar explanation from a mathematical perspective for role of a group's power structure in regulating the flow of information. They suggested that leadership is a self-sustaining process in which leaders occupy a central position within information channels and thus greater influence over the group's informational climate which among other things defines who is the leader. As such, the current study predicted that the relative control among members of a small-group would contribute to the observed coherence in response-patterns as they unfold over time.

Conflict, control, and closeness are each considered to limit the space of free movement to borrow a term from Lewin (1951), who developed the first topological models of small group dynamics long before sufficient methodology existed to test his ideas fully. Similarly, the vector fields proposed to exist within small groups by Lewin are considered here to be just that, vectors that may characterize the dynamic flows of information among members. Under the more contemporary rubric of self-organization, the 3-C's are considered to be emergent properties of small groups, arising out of coordinated exchanges of information among the members, and at the same time influencing subsequent coordination over time. The process is circular, with constraint, regulation, and perturbation emerging from the bottom-up, regulating from the top- 
down, and so on over time (Kauffman, 1995).

Unlike closeness and conflict, which are likely to regulate information exchanges though reciprocal pulls, control is a complementary process (Leary, 1957), pulling for opposite reactions from members in a dyad. When one member becomes more controlling, the field of information flow pulls the other member toward relative submission. This complimentary pull may help to explain why the status-systems of therapy groups emerges so quickly (Yalom, 1985) forming a sort of back-bone to a group's structure. It also suggests one of many areas where control, conflict, and closeness may dovetail with one another. Sustained leadership requires some measure of support (closeness) from above and below. Conversely, status-related conflicts may emerge when a member perceives another's actions as a threat to one's status. This is only one of a number of ways in which the 3-C's might interact as relationships evolve over time. As such, these three parameters were not assumed to be completely independent in their connection to response-patterns within the current study.

\section{Self-organization, entropy and fractals}

In order to understand the design and measures of the current study, some basic introduction to nonlinear dynamical systems (NDS) is necessary. For a more comprehensive introduction to NDS theory in psychology see Abraham and Gilgen, (1995); Guastello, (1995, 2001, 2002, 2004); and Robertson and Combs, (1995). Among the many theoretical constructs contained within NDS, self-organization, entropy, and fractals are most relevant to the current study. Self-organization ( $\mathrm{SO}$ ) is a process that occurs in open systems as they exchange information (also matter or energy in the case of physical processes) with neighboring systems. As was mentioned above, SO involves self-regulation, as a system tunes its own dynamic and evolutionary characteristics over time through complex feedback mechanisms. Self-organizing systems are able to increase or decrease their levels of disorder or entropy in response to evolutionary challenges and interactions with neighboring systems (Nicolis \& Prigogine, 1989; Prigogine \& Stengers, 1984). As such, the current degree of entropy within a group process is a potentially interesting dependent variable. Indeed, a number of empirical investigations and 
simulations have supported the viability of modeling interpersonal processes as self-organizing and entropic in family therapy (i.e., Granic, Hollenstein, Dishion, \& Patterson, 2003; Pincus, 2001) individual therapy (Badalamenti \& Langs, 2002; Tschacher, Scheier, \& Grawe, 1998), and group therapy (Brabender, 1997; Burlingame, Fuhriman, \& Barnum, 1995).

One hallmark of SO is the presence of an inverse power law (IPL) in the output of such systems:

$$
S=f^{-b}
$$

where $S$ is the size of an event, $f$ is the frequency of an event and $b$ (typical IPL's: $1<\mathrm{b}<2$ ) is the slope of the curve. In other words, one would expect many small change events and exponentially fewer large ones. This relationship may be most widely known in the size to frequency relationship observed in earthquakes, which fortunately are exponentially less likely to occur at higher magnitudes on the Richter scale (which is based on equation 1). In the case of earthquakes and other complex SO phenomena, the shape parameter of the curve $(b)$ defines the relationship between the size of an event and its frequency; $b$ is also the fractal dimension, which is a measure of the complexity of a system's dynamics (Philippe, 2000; Schroeder, 1991; West \& Deering, 1995). Higher fractal dimensions describe relatively steep curves, where there are more small events (relatively speaking) - small quasi-random percolations. Lower fractal dimensions describe relatively flat curves, with relatively more large scale collective events, indicating greater structure, coherence, or at the extreme - rigidity. For example, a fault that produced more large quakes compared to small ones would be more rigid and predictable - also more troubling for those living nearby. Conversely, a fault with many more small quakes compared to large ones would begin to approach chaotic activity.

IPL's are ubiquitous in the dynamic, time-dependent processes of natural systems, and have been observed across different scientific domains such as wait-times for emergency room visits (Philippe, 2000), timing of pulsar patterns from space, car clusters in traffic jams (Bak, 1996), heartbeat intervals, and the firing patterns of neurons (Bak, 1996; West \& Deering, 1995). This type of systemic output suggests that systemic evolution occurs through a series of 
discontinuous shifts (distributed as an IPL) or through more global systemic transformations as the system moves adjusts between different degrees of relative chaos and order. Within the current study, information flows in the group were expected to conform to this type of temporal fractal structure as evidenced by the existence of an IPL distribution in the magnitude of recurrence of the various turn-taking patterns; many small recurrences and exponentially fewer large ones.

When observed in physical structures, IPL's are often referred to as fractals, because their complex edges yield fractal dimensions which resist accurate measurement (West \& Deering, 1995). Branching patterns are fractal structures (i.e., trees, rivers, bronchial tubes), conforming to IPL distributions when one compares the frequency of a branch to its size exponentially more small branches when compared to large ones.

Within the current study, the structure of turn-taking patterns was predicted to conform to an IPL described by equation 1 above, whereby there would be exponentially more verbal turntaking patterns in the group discussion that recur very few times (i.e., one or two time repetitions within the discussion) compared to high-frequency patterns (i.e., ten or more repetitions within the discussion). The discovery of this type of structure would suggest that these patterns are generated through a process of self-organization, that group evolution involves the selfregulation of change or entropy within the group, and that group processes are somewhat predictable on a global level (i.e., fractal organization), yet at the same time highly complex on a moment-by-moment basis.

Finally, the generation of an IPL by an interpersonal system also would imply both structural and functional evolutionary significance. Such systems are thought to be poised in a dynamic region referred to as the edge of chaos (EOC) (Waldrop, 1992) because the behavior of these systems is almost chaotic. As a dynamic region, the EOC would afford groups with a mixture of coherence and complexity that would allow adaptation without annihilation and coherence without stagnation (Dooley, 1997), adaptive qualities observed in complex adaptive systems across the sciences. 
As esoteric as these ideas may seem, there is already some direct evidence for the existence of IPL's in small group processes. For example, Bales (1999) observed that the distribution of total acts initiated based on rank appears to be similar to an IPL distribution. Similarly, Guastello (1998; in press) found that the distribution of leadership scores fell close to an IPL as well. Both of these studies suggest that interpersonal control in small groups emerges from the complex interactions among members.

The current study will seek to extend these results by examining the structure within turntaking patterns rather than leadership per se. Once obtained, the amount of structure within any given pattern (defined as the number of times the pattern recurs during the discussion) will be examined for its correlation with conflict, closeness and control among those members involved in the particular pattern. If such correlations exist, it would suggest that these role and relational constructs are meaningfully related to the complex process that regulates the flow of information within the group.

The first hypothesis was that the discussion would display complex dynamics characteristic of self-organization. This was tested using three related measures of entropy Lyapunov dimensionality (a measure of turbulence), Shannon's entropy (a measure of information novelty), and fractal dimension (a measure of complexity), which is based on the slope of the IPL in the distribution of patterned recurrences. The presence of an IPL in turntaking patterns had not been investigated previously at the time of the present literature review. The second hypothesis contained three parts, predicting that conflict, closeness, and control among the members in a particular pattern would predict the frequency of recurrence for that pattern. Together with hypothesis 1 , this would suggest that these relational features contribute to coherence within the group by way of self-organizing group dynamics.

\section{Method}

\section{Participants and task}

The participants were six males, four African-Americans and two European-Americans, age 13-15, who participated in 16 weeks of court-ordered group therapy for youth sex-offenders. 
Each group session was 1.5 hours in length, and the group was closed beyond Session 2. The group format was structured and educational in nature with topics to be covered each week (i.e., empathy for victims). There were two group facilitators. The group members' parents were contacted by phone and by mail beginning at week 10 of the group, two weeks prior to collection of self-report data (Session 12). Of the ten group members, two declined to participate and two others dropped out of the group, leaving six members who participated in the single session analyzed for the current study. Specific information regarding the members' offenses and socioeconomic backgrounds were not collected, although it was known that youth in the program tended to come from low socio-economic urban neighborhoods.

The members were led as a group to the observation room at the start of Session 13. They were told that they would be observed by the principal investigator and their group therapist from behind the one-way mirror and reminded that they were expected to do their best to reach a consensus opinion on a series of therapeutic questions regarding sex offending. They were allowed to choose their own seats, which were arranged in a semi-circle with a radius of approximately six feet. The discussion was video-taped from behind a one-way mirror.

\section{Pattern analysis}

Each utterance was first coded based solely on speaker, each turn-at-speech in timesequence. The patterns in this series of turns-at-speech were analyzed using orbital decomposition (OD) to derive the three measures of entropy used in the current study. OD is based on symbolic dynamics, and was specifically designed for the analysis of categorical timeseries data (Guastello, et al., 1998; Guastello, 2000). The procedure involves three calculations in parallel: Shannon entropy $\left(H_{\mathrm{S}}\right)$, topological entropy $\left(H_{\mathrm{T}}\right)$, and a likelihood $\chi^{2}$ (with concomitant $\phi^{2}$ ) test of strings (patterns) of responses of varying length, $C$. One starts with $C=$ 1 (single utterances) and then increases in one utterance increments to examine longer and longer patterns of verbal turn-taking (i.e., $C=2,3,4 \ldots$ ). $H_{T}$, and $H_{\mathrm{S}}$ measured at each length are indicators of the degree of turbulence and novel information present within the discussion respectively. The $\chi^{2}$ and $\phi^{2}$ tests provide a statistical significance test and variance accounted 
for respectively for each increasing string-length, helping one to determine the optimal length at which to analyze patterning within the discussion.

The calculation of topological entropy $\left(H_{\mathrm{T}}\right)$ is based on the diagonal entries or trace of a hypothetical transition matrix at each length string length, $M C$. Each cell entry is binary, and indicates whether a particular pattern (general event) is followed in time by any other pattern. The trace (diagonal) of this matrix represents instances where a pattern is followed by itself in a consecutive period of time, which will be referred to here as a proximal recurrence. Guastello et al., (1998) derived the calculation of for $H_{T}$ by considering these proximal recurrences to be analogous to periodic orbits used in the calculation of entropy in ratio scale data from physical systems (Lathrop \& Kostelich, 1989).

To understand periodic orbits - imagine a bowl containing a single marble. If one were to shake the bowl (adding random noise to its surface) the marble would move around the basin (low point), making occasional periodic orbits. Now imagine bowl with two basins, there would be two distinct orbits; three basins, three orbits, and so on. When a system contains three or more basins sufficiently close to one another to allow for their interaction, the rolling marble would have the potential to display dynamics described by deterministic chaos (Newhouse, Ruell, Takens, 1978). This means that the marble's trajectories would be increasingly unpredictable further into the future, but the underlying system is completely deterministic defined by the dynamics of the interaction of three basins. Simply, the more basins one has, the more chaotic the motion becomes. In small group dynamics, proximal recurrences are considered to be analogous to orbits around a basin - the greater the variety of these orbits the more unpredictable the conversation flow will be.

The resulting equation for Topological entropy $\left(H_{\mathrm{T}}\right)$ based on the trace of $M^{C}$ is: $H_{\mathrm{T}}=\lim _{\mathrm{c} \rightarrow \infty}(1 / C) \log _{2} \operatorname{tr}\left(M^{C}\right)$

As the string length goes approaches infinity, $H_{T}$ approaches the base-2 logarithm of the maximum Lyapunov exponent, which is, in turn, the largest eigenvalue of $M^{C}$ (Guastello et al., 1998). Lyapunov Dimensionality ( $D_{\mathrm{L}} ;$ a common measure of chaosticity) is, therefore, 


$$
D_{\mathrm{L}}=e^{H_{\mathrm{T}}} \text {. }
$$

Calculation of Equations 2, and 3 are carried out for each increasing value of $C . H_{T}$ is expected to decrease as $C$ increases and eventually drop to zero as proximal recurrences become less likely for longer patterns based on simple combinatorial probabilities of single utterances. This drop to zero is the primary indicator of the asymptotic limit of $C$, providing the best means for determining the longest optimal string length for analyzing the discussion (Guastello et al., 1998).

The second entropy measure, Shannon entropy $\left(\mathrm{H}_{\mathrm{s}}\right)$, for a set of categories with unequal odds of occurrence is defined as:

$$
\mathrm{H}_{\mathrm{s}}=\sum_{\mathrm{i}=1}^{\mathrm{r}} \mathrm{p}_{\mathrm{i}}\left[\ln \left(1 / \mathrm{p}_{\mathrm{i}}\right)\right],
$$

where $p$ is the probability associated with each $(i=1$ to $r$ ) categorical outcome of the observation of interest. Shannon entropy may be conceptualized as the degree of novelty present within a categorical time series (Attneave, 1959; Shannon \& Weaver, 1949). As a concrete example, imagine that one is trying to figure out a word in a crossword puzzle based on individual letters. The more novel a letter is, such as $z$ or $x$, the more information it carries. Thus, the presence of a $z$ or $x$ in a crossword is very helpful toward finding the correct word because of the fact that it is used so infrequently. More common letters (i.e., $c$ or $b$ ) on the other hand would not provide much information to a puzzle-solver. Most simply, Shannon entropy conveys the degree to which a categorical time series contains relatively rare patterns as opposed to relatively commonplace patterns. As such, it could be considered to be a cousin of the likelihood $\mathrm{X}^{2}$. It is important to note that this degree of novelty is not nested in time as is topological entropy with its reliance on proximal-recurrences. This indifference to order is the main drawback for the sole use of Shannon entropy within the context of human interaction.

The calculation of the $\chi^{2}$ for goodness of fit, $\phi^{2}$, analogous to variance accounted for, is carried out for each value of $C$. It determines whether the behavior strings observed in the data occur at rates different from chance, where chance is simply the combinatorial probability of 
each categorical element in the string. These statistical indices help to validate the selection of the optimal $C$, which as noted above is determined as the length of a string one step before the step at which $H_{T}$ drops to zero.

Once the optimal string length was determined, the presence of an IPL and calculation of fractal dimension was carried out. Again, this measure of complexity is based on the slope of the logistic curve describe by equation 1 above, describing the number of utterance-patterns at each different frequency of recurrence. The predicted ratio is the presence of few high recurring patterns and many low recurring patterns during the discussion. Nonlinear regression was used to test the shape of the distribution and the exponent of the curve $(b)$ (the rate at which the frequency of highly repetitive patterns decays toward 0; Phillippe, 2000). The current model was tested with a statistical version of equation 1, expressed in equation five as:

$$
\mathrm{Y}=\mathrm{a} \mathrm{X}^{-\mathrm{b}}
$$

where $\mathrm{X}$ is the number of recurrences for a given pattern (analogous to the magnitude of the recurrence phenomenon), $\mathrm{Y}$ is the frequency at which one observes each particular value of recurrence, $a$ is an intercept, and $b$ is a nonlinear regression weight representing the slope of the 1/f curve and can be used as an estimate of fractal dimension. Within the nonlinear regression analysis, Equation 5 was first translated into a logarithmic (e.g., linear) scale represented by Equation 6:

$$
\ln (Y)=\ln (a)-b(\ln ) X
$$

\section{Measures}

Conflict, closeness, and control were each measured through self-report and observationbased indices. The self-report measures were administered at the end of the session 12, one week prior to the analyzed discussion to reduce the possible impacts of testing on the group dynamics. A brief (seven-item) measure designed to assess conflict in informal peer 
relationships was developed for the current study. The first two items, addressing anger and distrust, were taken from the group climate questionnaire (MacKenzie, 1981) and were adapted to query present conflict within dyads (each member answered each item based on his relationship to each other member) rather than the group as a whole. The additional five items were written to measure broader aspects of the conflict experience, including: disagreement with statements; disagreement with behavior; disagreement with values; and the two modes of conflictual response, avoidance and confrontation. Because the scale was new, its reliability was assessed on an independent sample of college undergraduates based on their current relationships with their roommates. Both test-retest reliability $(r=.98, p<.001, N=43)$ and internal consistency ( $\alpha=.88, N=74)$ were strong.

The bonding-to-participants subscale from the Group Bond Questionnaire (GBQ; Piper, Marrache, Lacroix, Richardsen \& Jones, 1983) was used to measure self-reported closeness. It has been shown to have moderate reliability and validity, which is considered good in comparison to other comparable measures (Hoover, 1993; Piper et al., 1983). Like conflict, this questionnaire queried each member's closeness with each other member - resulting in a total of 30 (6 members x 5 dyadic relationships) one-directional dyad scores.

Interpersonal control was assessed first by asking the participants were to rank each other participant for leadership on a scale from one to ten. Next, each member completed 18 selfreport items comprising the interpersonal control dimension of the SYMLOG scale, which has shown good reliability and validity (Bales, 1970) in assessing perceptions of leadership in small group contexts.

The observation-based scores for the 3-C's in the current study were derived from a coding scheme designed for the current study (see appendix A). The current scheme was based on prior schemes (Mark, 1971; Ericson \& Rogers) used in family systems research based in communication theory (Bateson, 1958; Lichtenberg \& Heck, 1986), designed to identify the underlying relational meaning of verbal statements. Each utterance previously identified and coded only for speaker in the pattern analysis described above was subsequently coded as one of 
three mutually exclusive categories: conflict, closeness, or control. Conflicting statements were defined as disagreements with or disconfirmations of another member's statement (see Ericson \& Rogers, 1973 for original definitions and rationales), whereas supportive statements (i.e., “That's a good idea") were defined as conveying closeness.

Once an utterance was identified as conveying either conflict or closeness, scores were assigned, ranging from 1 to 5, with points assigned based on: 1) how global the statement was; 2) whether the statement overlapped with the previous statement; 3) the presence of positive or negative affect; or 4) or whether the statement involved an implicit threat. For example, basic support or non-support of an idea (i.e., "That's a good idea" or "That's a bad idea") was assigned one point for closeness or conflict respectively. Support or non-support of a person or the person's general beliefs (i.e., "You come up with good ideas" or "You come up with bad ideas") was assigned a score of two. The presence of positive (happy or enthusiastic) or negative (angry or frustrated) affect led to the addition of one point, yielding a total of either 2 (i.e., frustrated criticism of an idea) or 3 (frustrated criticism of another member) for the utterance. Similarly, if the statement interrupted the previous statement a bonus point was added - as in the case of overlapping agreement or interruptive disagreement. Any threat (with the minimum threshold for threat defined as "Shut up.") automatically resulted in a minimum score of 4 for conflict, or 5 if the threat involved interruption. In parallel, level-4 closeness ( 5 with interruption) was scored if a member defended another member against such verbal attacks (i.e., "No, you shut up.”). With the inclusion of the target(s) for each of these statements, observation-based conflict and closeness scores were tallied for each member with each other member (one-way dyadic scores) based on the sum of scores for the entire discussion. This yielded a total of 30 possible dyad scores (6 members x 5 possible relationships) as was the case for the self-report measures. To control for individual differences in response-styles (relative use of conflicting statements) closeness and conflict scores (both self-report and observation-based) were standardized based on each participant's mean and standard-deviation for his 5 dyadic relationships. 
Observational scoring of control for each member was simply the tally of informationgiving, instructions, and topic-changing statements made by that member (Ericson \& Rogers, 1973). Scores for controlling utterances were all scored as 1 point and tallies were completed for each individual to provide a total score.

\section{Reliabilities of coded responses}

The entire discussion was coded by the PI and a second rater (a clinical psychology graduate student) coded a ten-minute section (from 30 to 40 minutes - selected at random) to assess reliability of the scheme. Cohen's Kappa $(K)$, was calculated for speaker $(K=.82)$, typeof-speech (3-C's, $K=.72)$ and affect $(K=.66)$, which were considered sufficiently high to support the reliability of the codes. In addition, Pearson product-moment correlations across raters were conducted for control (mean $r=.93$; range $=.80-1.0 ; n=6)$, closeness (mean $r=$ $.76 ;$ range $=.13-1.0 ; n=29$ ) and conflict (mean $r=.91 ;$ range $=.44-1.00 ; n=24 ; n<30$ is due to a lack of expressed closeness and conflict between some members over the course of the discussion). Overall, all of the correlations were statistically significant $(p<.05)$, and the averages were large. Disagreements between raters were discussed, reconciled and applied to similar instances in other sections.

Each pattern that eventually emerged from the OD analysis contained a sequence of individuals' responses. As such, scores on each of the 3-Cs were summed for each pattern based on the scores for the members involved in each particular pattern. For example, if a given pattern contained four members, each with dyadic conflict scores of 20 , the total conflict level for that pattern would be $80(20 \times 4)$. The sums for each pattern were then tested for correlations with the natural log (a linear conversion) of the frequency of recurrence for that pattern, where the pattern (not the individual) was the unit of analysis. For example, if pattern A had a high conflict score based on the conflict among the members in that pattern, a high level of recurrence was predicted for that particular pattern. 


\section{Results}

For the sake of clarity each of the group members is designated by an alphabetical code name indicating relative use of control statements. $\mathrm{Al}$, made $27 \%$ of the total control statements $(N=$ 402) Bob made 25\%; Cal made 18\%; Dan made 17\%; Ed made $8 \%$ and Fred made $4 \%$. Consistent with past research (as reviewed by Bales, 1999) overall speaker frequencies corresponded to control frequencies for all members except Dan, with Al making 23\% of the total utterances, Bob 21\%, Cal 20\%, Dan 24\%, Ed 10\%, and Fred 3\%. The utterances tended to be rapid and short with 1214 utterances in the one-hour and 35-second conversation, yielding a mean utterance length of three seconds. This fast pace was likely related to the large number of conflicts made by each participant $(n=809)$ and interruptions $(n=136)$, with less closeness $(n=$ 521 ; with the majority of these statements involving third-party defenses against prior conflicting statements).

The OD procedure (see Table 1) indicated that the number of proximal recurrences $\left(R_{p}\right)$ dropped to zero past the critical length of $C=4$, and the $\phi^{2}$ value was large, exceeding all previous values. The anomaly of $\phi^{2}$ values greater than 1.0 has been described as resulting from a violation of the assumption of a 2 x 2 matrix (Guastello et al., 1998; Pincus, 2001). It is inconsequential for comparisons because the violation impacts each string length equally. Hypotheses 1 and 2 were supported by the variety of proximal $\left(R_{p}=7\right)$ and distal recurrences $\left(R_{d}\right.$ $=924)$ at $C=4$ as well as the entropy measures, which were characteristic of coherent yet complex processes $\left(\mathrm{H}_{\mathrm{S}}=6.44\right.$ and $\left.\mathrm{D}_{\mathrm{L}}=2.01\right)$. The most frequently recurring patterns are listed in Table 2.

Insert Tables 1 and 2 Here

Hypothesis 1 also predicted that the frequency distribution for utterance-patterns would conform to an IPL distribution as defined by Equation 1:

$$
\mathrm{Y}=\mathrm{a} \mathrm{X}^{-\mathrm{b}}
$$

where $X$ is the number of recurrences for a given pattern at $C=4$ (the magnitude of the 
recurrence phenomenon) and $Y$ is the frequency at which each of these recurrences phenomena occur. Parameters $a$ and $b$ were estimated as regression weights (Philippe, 2000). Again, $b$ represents the slope of the 1/f curve and also an estimate of fractal dimension. Equation 5 was first translated into a logarithmic function:

$$
\ln (Y)=\ln (a)-b(\ln ) X
$$

The nonlinear regression conducted based on Equation 6 accounted for $95 \%$ of the variance within the distribution of patterned recurrences $\left(R^{2}=.95\right.$; see Figures $\left.1 \& 2\right)$. Parameter $b$, the fractal dimension, was estimated at 1.64 with a $95 \%$ confidence interval ranging from 1.62 (lower) to 1.66 (upper). This value is close to the measure of Lyapunov dimensionality (2.02) listed in Table 1, and is within the typical range for EOC processes (Bak, 1996; Kauffman; 1995).

Insert Figures $1 \& 2$ Here

Before testing Hypothesis 2, the self-report and observational measures were assessed for convergent and discriminant validity (Campbell \& Fiske, 1959). The two conflict measures were sufficiently consistent $(r=.52, p<.01)$, and were combined into a single index. Control and closeness were not convergent across methodologies, however. This precluded the combination of these scores across methodologies, and necessitated a selection of either self-report or observation-based scores for subsequent analyses. A number of factors pointed toward the decision to select the observation-based measures for subsequent analyses. For example, there was no clear agreement among the group members', or the therapists' for that matter (who's ratings served as a manipulation check), ratings of control. Similarly, the self-report ratings for closeness showed some problems as well, such as being low across members with little variation.

To test Hypothesis 2 (see Table 3) scores on the 3-C's for each pattern were calculated by summing across the four members involved in the pattern. The natural-log of the frequency for a given pattern was used to translate frequency into an interval scale prior to regression analyses. The correlations for control $(r=.58, p<.001)$, closeness $(r=.36, p<.001, N=1211)$, and 
conflict among group members $(r=.51, p<.001)$ each were significant. A stepwise multiple regression was conducted $\left(R^{2}=.48, p<.0001\right)$ with each of the predictors contributing unique variance (conflict $\beta=.49, p<.0001$; closeness $\beta=.29, p<.0001$; control $\beta=.22, p<.0001$ ).

The use of observation-based scores alone for closeness and control in these analyses opens the door to problems related to method variance - most significant potentially the fact that both predictors and the criterion in this case are each related to speaker base-rates (i.e., more talkative members might score higher on closeness and control and also be involved in more recurrences). The significant $\mathrm{X}^{2}$ value at $\mathrm{C}=4$ (see Table 3) provides some control for this possibility, indicated that patterning occurred far more than would be expected simply based on speaker base-rates. Nevertheless, a more stringent multiple-regression analysis was conducted by first entering expected frequencies (the combinatorial probability for a given pattern based on the base-rates for members involved multiplied by the total number of patterns at $C=4$ ) for each pattern patterns into the regression equation first, followed by each of the three C's in the order of their weights reported above. The resulting equation accounted for 49 percent of the variance in log-frequencies for patterns at $C=4\left(R^{2}=.49, p<.0001\right)$. The strongest predictor was indeed expected frequency $(\beta=.53, p<.0001)$, followed by observed closeness $(\beta=.16, p=.0002)$ and finally by the combined conflict measure $(\beta=.14, p=.01)$. Control was dropped from the equation due to a lack of unique variance $(\beta=.07, p=.60)$. Overall, these results suggest that speaker base-rates are interesting in and of themselves, yet they can not account completely for the observed connections of closeness and conflict with patterning.

Insert Table 3 Here

\section{Discussion}

\section{Interpersonal Self-organization}

Together, the entropy measures used to test Hypothesis 1 supported the fundamental notion that there would be coherent yet complex patterns of interaction present within this small 
group discussion. This finding is consistent with two previous studies of other small group discussions (Guastello, 2000; Guastello et al., 1998; Guastello, 2000; Pincus, 2001). These results extended the theory of self-organizing systems to the specific context of interaction in group therapy and provided the first published evidence of an IPL in group dynamics.

Hypothesis 2 examined the connections among this process of self-organization and some central aspects of roles and relationships. Specifically, control, closeness, and conflict among members each were independently related to coherence within response patterns - lending further support to the 5-R model proposed by Pincus (2001). On an applied level, the results provide an evidence-base for the longstanding practice of making clinical inferences about relationships based on interactive response patterns observed within conjoint therapy sessions.

Whether one uses older concepts of field diagrams (Lewin, 1951) or attractor dynamics (Guastello, 2002), the dynamical measures and IPL observed in the current study reflect a deterministic field of information flow that is channeled by the group's relational structures (the 3-C's). This system of relationships (or attractor) would be expected to evolve according to EOC dynamics involving discontinuous changes or transitions through chaos. This notion is consistent with the goals of process-oriented psychotherapies, which strive for deep, irreversible change and growth through processes such as conflict resolution, the development of egalitarian power structures, or flexible movement between intimacy and autonomy.

The three C's

The clearest conclusions within the current study were found for conflict, both in terms of confidence in the measured construct and in the strength of the correlations with patterning. Recall that conflict is often a precursor to hostility (e.g., Leary, 1957), suggesting that hostility pulls for interactive reciprocity, a notion that has been demonstrated clearly within the marital context (Gottman, 1991; Gottman, 1999). The current results suggest that conflict is a process involving reciprocal pulls among individuals, and extend these past results by suggesting that conflict has a broader role in generating coherence within interpersonal processes. This conclusion is in line with Yalom's (1985) positive view of the emergence of conflict within the 
evolution of therapy groups.

The results of the current study add initial evidence for a deeper understanding of conflict as well, involving the dual processes of creation (coherence) and destruction (change).

Subsequent studies involving more than one group discussion could examine the evolutionary energy bound up in interpersonal conflict, the similarity in processes of internal and interpersonal conflicts, and the possibility that cascades across the group and individual level might account for the efficacy of group therapy.

Consistent with past theory and research (e.g., Bales, 1970; Lewin, 1951; Yalom, 1985), interpersonal control, which is a marker of leadership, was also associated with coherence within the current study. This result, in combination with other evidence for interpersonal SO, suggests that change in the control structures of a group can engender systemic adaptation to greater levels of adaptive functioning. Future research might examine these hypothetical adaptive processes over the course of therapy.

Finally, observed closeness among dyads was associated with SO patterning, suggesting that it too could play a key role within group adaptation. These results do dovetail nicely with past theory relating to triangulation (e.g., Bowen, 1974), cohesion (e.g., Yalom, 1985), and therapeutic alliance (Grencavage \& Norcross, 1990; Orlinsky \& Howard, 1986; Tschacher et al., 1998). It is likely that the constellation of bonds among group members impacts their ability to openly address and resolve conflicts. On a systemic level then, the coherence creating nature of closeness might provide necessary structure as relationships evolve through conflict resolution. Again, this question could be addressed in studies involving multiple group sessions.

\section{Directions for future research}

The most serious threat to the internal validity of the current study rested in problems obtaining convergence between the observation-based and the self-report measures of control and closeness, which resulted in solitary reliance on observation-based measures for these constructs. As a result, replications should employ a post-test of any self-report measures used so that the accuracy of member's ratings can be judged more carefully. Additional 
improvements may include rating only the top two leaders (Guastello, 1998), developing a better measure of closeness, employing more measures for each construct and employing more raters to code longer sections of discussion.

While the results of the current study suggested that the 3-C's are associated with selforganization, which suggests that systemic cause is at work, the issue of cause could be more firmly established by observing changes in the complexity of response patterning following experimental manipulations. For example, Guastello (2002) has performed a series of studies using different analytic techniques for examining changes in complex production flows within hierarchical organizations. Similarly, response patterns could be examined after the experimental induction of conflict, power sharing, or increasing intimacy.

It would be particularly interesting to observe bifurcations (discontinuous changes) in group structure over time. This could be accomplished by examining changes in patterning across beneficial therapeutic turning points. For example, Hayes and Strauss (1998) have had some success in identifying qualitative bifurcations in the form of sudden disorganization and worsening of symptoms immediately preceding improvements in functioning during individual therapy processes. Similar changes could be sought within group therapy process. Conversely, therapeutic interventions could be targeted at specific rigid patterns that were identified by OD; one would then examine the relative impact on group structure and treatment outcomes.

The door to these vast, relatively unexplored empirical landscapes has been opened through the development of methodologies used within the current study that allow for the identification of recurring patterns in categorical time series and the quantification of the complexity within those patterns. So far, the theoretical maps of these landscapes within group dynamics seem to rest firmly within NDS principles (Guastello, 2002), which might allow for a more complex understanding of group processes.

Hopefully, the current study will represent a step toward the integration of research in group process and the various interventions that utilize group process - from families to board rooms. The glue that allows for this type of broad integration is NDS, which may help to 
provide a deeper understanding of group behavior, group structure, and systemic evolution. Furthermore, as a general systems theory, NDS opens the door to an even broader integration for interpersonal theory beyond psychology to universal principles of systemic organization and evolution across the sciences (Guastello, 1995; Kauffman, 1995). 


\section{References}

Abraham, F.D. \& Gilgen A.R. (Eds.) (1995). Chaos theory in psychology. Westport CT: Greenwood Press.

Arrow, H., McGrath, J.E., \& Berdahl, J.L. (2000). Small groups as complex systems: Formation, coordination, development, and adaptation. Thousand Oaks, CA: Sage.

Asch, S.E. (1956). Studies of independence and conformity: A minority of one against a unanimous majority. Psychological Monographs, 70, (9), (Whole No. 416).

Attneave, F. (1959). Applications of information theory to psychology: A summary of basic concepts, methods, and results. New York: Hult, Rinehart, and Winston.

Badalamenti, A.F. \& Langs, R.J. (1992). The thermodynamics of psychotherapeutic communication. Behavioral Science, 37, 152-180.

Bak, P. (1996). How nature works: The science of self-organized criticality. New York: Springer-Verlag.

Baldwin, M. W. (1995). Relational schemas and cognition in close relationships. Journal of Social and Personal Relationships, 12, 547-552.

Bales, R.F. (1953). A theoretical framework for interaction process analysis. In D. Cartwright and A. Zander (Eds.), Readings in Social Psychology (pp. 29-38). Evanston, IL: Row, Peterson.

Bales, R.F. (1970). Personality and interpersonal behavior. New York: Holt, Reinhart \& Winston.

Bales, R.F. (1999). Social interaction systems: Theory and measurement. New Brunswick, NJ: Transaction Publishers.

Baron, R.M., Amazeen, P.G., \& Beek, P.J. (1994). Local and global dynamics of social relations. In Robin R. Vallacher \& Andrzej Nowak (Eds.). Dynamical systems in social psychology (111-137). Academic Press: New York.

Bateson, G., (1958). Naven, $2^{\text {nd }}$ ed., Stanford, CA: Stanford University Press.

Bowen, M. (1974). Toward a differentiation of self in one's family of origin. In F. Andres and J. 
Lorio (Eds), Georgetown family symposium, vol. 1. Washington, D.C.: Department of Psychiatry, Georgetown University Medical Center.

Brabender, V. (1997). Chaos and order in the psychotherapy group. In F.D. Masterpequa and P.A. Perna (Eds.) The psychological meaning of chaos: Translating theory into practice (pp. 225-252). Washington, DC: American Psychological Association.

Burlingame, G.M., Fuhriman, A., \& Drescher, S. (1984). Scientific inquiry into small group process: A multidimensional approach. Small Group Behavior, 15, 441-470.

Burlingame, G.M., Fuhriman, A., \& Barnum, K.R. (1995). Group therapy as a nonlinear dynamical system: Analysis of therapeutic communication for chaotic patterns. In F. D. Abraham and A.R. Gilgen (Eds.), Chaos Theory in Psychology (pp. 87-105). Westport, CT: Greenwood Press.

Campbell, D.T., \& Fiske, D. (1959). Convergent and discriminant validation by the multitraitmultimethod matrix. Psychological Bulletin, 56, 81-105.

Dooley, K.J. (1997). A complex adaptive systems model of organization change. Nonlinear Dynamics, Psychology, and Life Sciences, 1, 69-97.

Ericson, P., \& Rogers, L. (1973). New procedures for analyzing relational communication. Family Process, 12, 245-267.

Festinger, L. (1954). A theory of social comparison processes. Human Relations, 7, 117-140.

Freud, S. (1905). Three essays on the theory of sexuality. In J. Strachey (trans. and ed.) The complete psychological works, vol. 7. New York: Norton, 1976.

Gottman, J.M. (1991). Chaos and regulated change in families: A metaphor for the study of transitions. In P.A. Cowan and M. Hetherington (Eds.), Family transitions (pp. 247-272). Hillsdale, NJ: Lawrence Erlbaum Associates.

Gottman, J.M. (1999). The marriage clinic: A scientifically based marital therapy. New York: WW Norton Co.

Gottman, J.M., Murray, J.D., Swanson, C.C., Tyson, R., Swanson, K.R. (2002). The mathematics of marriage: Dynamic nonlinear models. Cambridge, MA: MIT Press. 
Granic, I., Hollenstein, T., Dishion, T.J., \& Patterson, G.R. (2003). Longitudinal analysis of flexibility and reorganization in early adolescence: A dynamic systems study of family interactions. Developmental Psychology, 39 (3), 606-617.

Guastello, S.J. (1995). Chaos, catastrophe, and human affairs: Applications of nonlinear dynamics to work, organizations, and social evolution. Mahwah, NJ: Lawrence Erlbaum. Guastello, S.J. (1998). Self-organization in leadership emergence. Nonlinear Dynamics in Psychology and Life Sciences, 2, 303-316.

Guastello, S.J. (2000). Symbolic dynamic patterns of written exchanges: Hierarchical structures in an electronic problem-solving group. Nonlinear Dynamics, Psychology, and Life Sciences, 4, 169-189.

Guastello, S.J. (2001). Nonlinear dynamics in psychology. [Invited review article] Discrete Dynamics in Nature and Society, 6, 11-29.

Guastello, S.J. (2002). Managing emergent phenomena: Nonlinear dynamics in work organizations. Mahwah N.J: Lawrence Erlbaum.

Guastello, S.J. (2004). Progress in applied nonlinear dynamics: Welcome to NDPLS Vol. 8. Nonlinear Dynamics, Psychology, and Life Sciences, 8, 1-16.

Guastello, S. J. (in press). Statistical distributions and self-organizing phenomena: What conclusions should be drawn? Nonlinear Dynamics, Psychology, and Life Sciences, 9.

Guastello, S. J., Hyde, T., \& Odak, M. (1998). Symbolic dynamic patterns of verbal exchange in a creative problem solving group. Nonlinear Dynamics, Psychology, and Life Sciences, 2, $35-58$.

Hare, P. \& Davies, M.F. (1994). Social interaction. In A.P. Hare, J.J. Blumberg, M,F. Davies \& M.V. Kent (Eds.), Small group research: A handbook (pp. 169-194). Norwood, NJ: Ablex.

Hayes, A.M., \& Strauss, J.L. (1998). Dynamic systems theory as a paradigm for the study of change in psychotherapy: An application to cognitive therapy for depression. Journal of Consulting and Clinical Psychology, 66, 939-947. 
Kauffman, S.A. (1995). At home in the universe. NY: Oxford.

Kiesler, D. J. (1983). The 1982 interpersonal transaction circle: A taxonomy for complementarity in human processes. Psychological Bulletin, 77, 421-430.

Kiesler, D.J. (1996). Contemporary interepersonal theory and research: Personality, psychopathology, and psychotherapy. New York: John Wiley \& Sons.

Lathrop, D.P., \& Kostelich, E.J. (1989). Characterization of an experimental strange attractor by periodic orbits. Physics Review, 40, 4028-4031.

Leary, T. (1957). Interpersonal diagnosis of personality: A functional theory and methodology for personality evaluation. New York: Ronald Press.

Lewin, K. (1951). Field theory in social science. New York: Harper Bros.

Lichtenberg, J.W., \& Heck, E.J. (1986). Analysis of sequence and pattern in process research, Journal of Counseling Psychology, 33, 170-181.

MacKenzie, R.M. (1981). Measurement of group climate. International Journal of Group Psychotherapy, 31, 287-296.

Mandelbrot, B. (1983). The fractal geometry of nature. New York: W.H. Freeman.

Mark, R.A. (1971). Coding communication at the relationship level. The Journal of Communication, 21, 221-232.

Nichols, M.P., \& Schwartz, R.C. (1998). Family therapy: Concepts and methods (4 ${ }^{\text {th }}$ ed.). Boston, MA: Allyn \& Bacon.

Nicolis, G., \& Prigogine, I. (1989). Exploring complexity. New York: Freeman.

Newhouse, R., Ruell, D., \& Takens, F. (1978). Occurrence of strange attractors: An axiom near Quasi-periodic flows on $\mathrm{T}^{\mathrm{M}}, \mathrm{M} \geq 3$. Communication in Mathematical Physics, 64, 35-41.

Orlinksy, D.E., \& Howard, K.I. (1986). Process and outcome in psychotherapy. In A.E. Bergin \& S.L. Garfield (Eds.), Handbook of psychotherapy and behavior change $\left(3^{\text {rd }} \mathrm{ed}.\right)(\mathrm{pp}$. 311-381). New York: Wiley.

Philippe, P. (2000). Epidemiology and self-organized critical systems: An analysis in waiting times and disease heterogeneity. Nonlinear Dynamics, Psychology and Life Sciences, 4, 
275-297.

Pincus, D. (2001). A framework and methodology for the study of non-linear, self-organizing family dynamics. Nonlinear Dynamics, Psychology and Life Sciences, 5, 139-174.

Piper, W.E., Marrache, M, Lacroix, R., Richardsen, A.M., \& Jones, B.D. (1983). Cohesion as a basic bond in groups. Human Relations, 36, 93-108.

Prigogine, I., \& Stengers, I. (1984). Order out of chaos: Man's new dialog with nature. New York: Bantam.

Schroeder, M. (1991). Fractals, chaos, power laws. New York: Freeman.

Stewart, I. (1989). Does god play dice? The mathematics of chaos. Oxford, UK: B. Blackwell.

Shannon, C.E., \& Weaver, W. (1949). The mathematical theory of communication. Urbana, IL: University of Illinois Press.

Tschacher, W., Scheier, C., \& Grawe, K. (1998). Order and pattern formation in psychotherapy. Nonlinear Dynamics, Psychology, and Life Sciences, 2, 195-216.

Waldrop, M.M. (1992). Complexity: The emerging science at the edge of chaos. New York: Simon and Schuster.

Ward, M. (1995). Butterflies and bifurcations: Can chaos theory contribute to our understanding of family systems? Journal of Marriage and the Family, 57, 629-638.

West, B.J., \& Deering, B. (1995). The lure of modern science: Fractal thinking. New Jersey: World Scientific.

Yee, P. L., Santoro, K. E., Paul, J. S., \& Rosenbaum, L. B. (1996). Information processing approaches to the study of relationship and social schemata. In Gregory R. Pierce, Barbera R. Sarason and Irwin G. Sarason (Eds.): Handbook of social support and the family (pp. 25-42). Plenum: New York. 
Table 1. Complexity and Entropy Indicators from OD Analysis ${ }^{\mathrm{a}}$.

\begin{tabular}{lllllllll}
\hline$C$ & $R_{p}$ & $R_{d}$ & $H_{t}$ & $D_{l}$ & $H_{s}$ & $\chi^{2}$ & $\phi^{2}$ & $N$ \\
\hline 1 & 5 & n.a. & 2.33 & 10.07 & 1.69 & 149.44 & 0.12 & 1214 \\
2 & 22 & 1189 & 2.24 & 9.48 & 3.17 & 333.63 & 0.28 & 1213 \\
3 & 18 & 1093 & 1.39 & 4.04 & 4.70 & 792.72 & 0.65 & 1212 \\
4 & 7 & 924 & 0.70 & 2.01 & 6.44 & 1243.0 & 1.03 & 1211 \\
5 & 0 & 611 & undefined & undefined & 10.79 & 1409.7 & 1.17 & 1210 \\
\hline
\end{tabular}

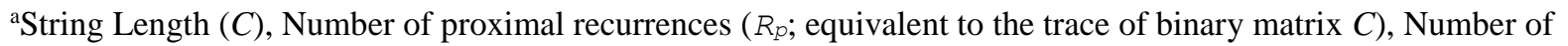
Distal recurrences $\left(R_{d}\right)$ Topological Entropy $\left(H_{\mathrm{t}}\right)$, Lyapunov Dimensionality $\left(D_{1}\right)$, Shannon Entropy $\left(H_{\mathrm{S}}\right), \chi^{2}, \phi^{2}$ and Number for Strings for $C=1$ to $C=5$.

Table 2. Primary Strings ${ }^{\mathrm{a}}$ Identified at $C=4$.

\begin{tabular}{lcccc}
\hline & Observed & Expected & \multicolumn{2}{c}{ \# of Recurrences } \\
N $\quad$ String & Frequency & Frequency & Distal & Proximal \\
\hline 1. BABA & 14 & 2.8 & 12 & 1 \\
2. DCDA & 13 & 3.2 & 12 & 0 \\
3. DBAB & 13 & 3.0 & 12 & 0 \\
4. BDBA & 13 & 3.0 & 12 & 0 \\
5. CDAC & 12 & 3.2 & 11 & 0 \\
6. CDAD & 11 & 3.2 & 10 & 0 \\
7. DACA & 11 & 3.1 & 10 & 0 \\
8. BDBD & 11 & 3.1 & 10 & 0 \\
9. BABD & 11 & 3.0 & 10 & 0 \\
10. ACDA & 11 & 3.1 & 11 & 0 \\
11. ACAC & 11 & 2.6 & 9 & 1 \\
12. ABAB & 11 & 2.8 & 8 & 2 \\
\hline
\end{tabular}

${ }^{a}$ The letters represent the first letter of each group member ranked in order of observed control, Al, Bob, Cal, Dan, Ed and Fred. Also listed are: observed and expected frequencies for patterns along with the number of distal and proximal recurrences.

Table 3. Results from bivariate and multivariate correlations ${ }^{\mathrm{a}}$.

\begin{tabular}{|l|l|l|}
\hline & Bivariate & Multivariate- $R\left(R^{2}=.48\right)$ \\
\hline $\begin{array}{l}\text { Observed control and } \\
\ln (\mathrm{f})\end{array}$ & $r=.58, p<.001$ & $\beta=.22, p<.0001$ \\
\hline $\begin{array}{l}\text { Observed closeness and } \\
\ln (\mathrm{f})\end{array}$ & $r=.36, p<.001$ & $\beta=.29, p<.0001$ \\
\hline $\begin{array}{l}\text { Combined conflict and } \\
\ln (\mathrm{f})\end{array}$ & $r=.51, p<.001$ & $\beta=.49, p<.0001$ \\
\hline
\end{tabular}

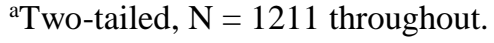


Figure 1. A plot of the number of different patterns ( $\mathrm{Y}$-axis) that recur at various frequencies (Xaxis) at $C=4$, illustrating an IPL distribution with $b=1.6$. Only one pattern that recurred as many as 14 times, while there were 212 different patterns that were occurred only once.

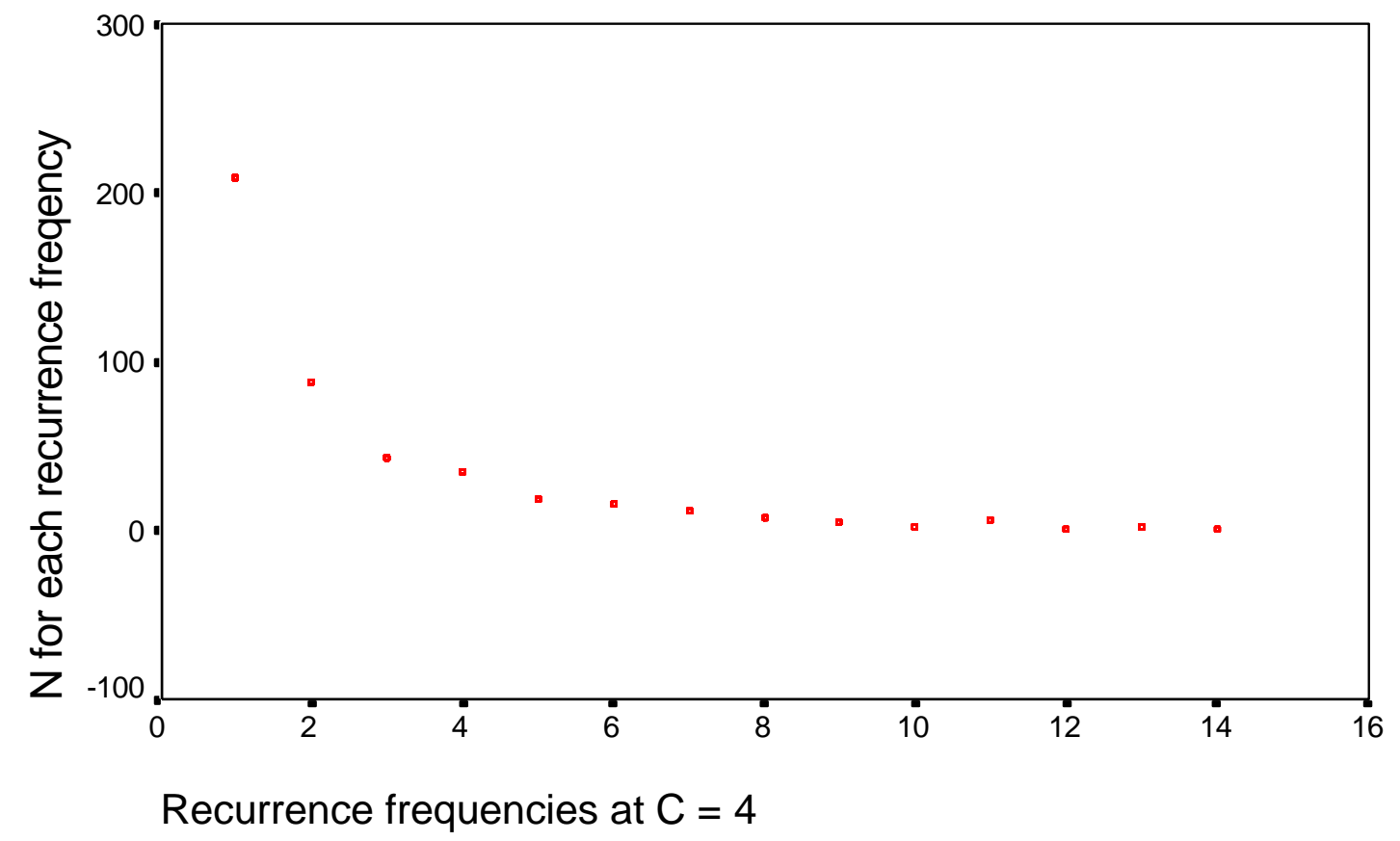

Figure 2. The same plot as Figure 1 with axes shown in logarithmic scales.

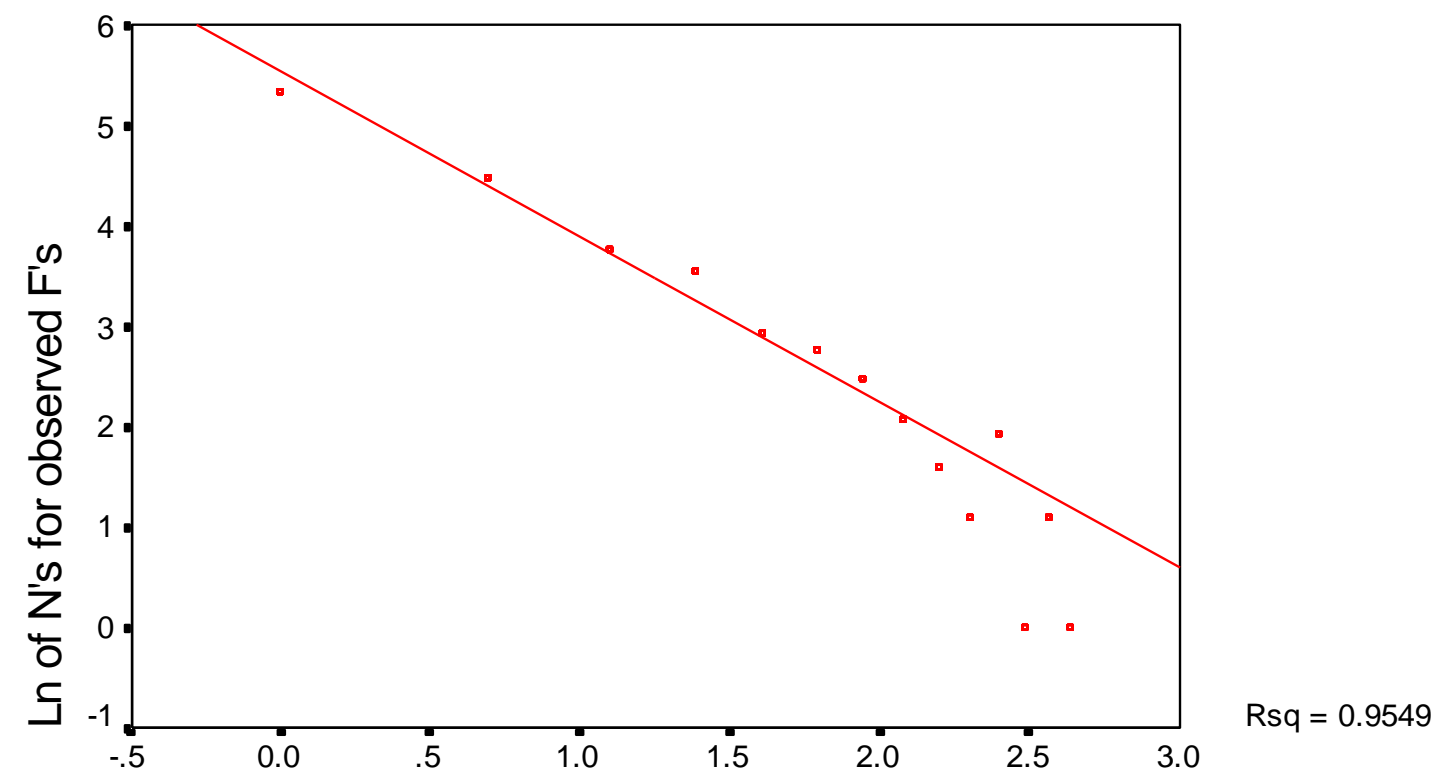

Natural log of observed frequencies 
Appendix A

\title{
Coding Scheme for Group Dynamics and the Three C's
}

\author{
Coding Speaker
}

Speaker (1-n): Assign a number to each speaker based on seating position from left to right (from your perspective). Record the number of the current speaker in column 1 (see record form) for each turn at speech based on rules for utterance coding below.

\section{What is an utterance?}

Record a code in each category for each utterance. An utterance is operationally defined as a unit of speech made by a single speaker. More specifically, an utterance has occurred and should be coded if any of the following three criteria has been met: 1) A statement is made that has contextual meaning (see below) or a subject (i.e., "I want to do some coding!") and object (i.e., I want to do some coding!" and is initiated during a period of silence. 2) A talked-over (see below) statement continues until both a subject and object have been stated (see exception for full overlap below). Or 3) Any verbal statement is made (no matter whether it is incomple) that elicits a response (verbal or non-verbal) from another group member. Remember, if someone looks toward the speaker in response to words, they spoke.

Tip: Focus on words. "sighs," "grunts," or coughs, as well as unintelligible mumbles that elicit no response, do not count. The benchmark for the minimum language to be coded would be "um hmm" expressing agreement or a "hmmm?" expressing a question. Non-verbal communications (looks, gestures) are never coded, even if they elicit a response from another member.

A new utterance always begins when there is a change in speaker, either through turn taking or interruption.

Any verbal behaviors that represent thinking out loud that elicit no response from any other member should not be scored because they are theoretically below the threshold for interactive behavior. It may be hard to tell at times if someone is thinking out loud or is communicating. As a rule of thumb, if you can make out half or more of what the speaker is saying, you can assume that other group members can as well. If you have an inaudible whisper, it is not really an utterance. Noverbal cues (i.e., looking up) might help you decide as well. But remember, if these types of responses elicit a response from another member, they theoretically have crossed the threshold of the group's attention, and should be scored.

Examples:

SPEAKER 1: Well, I wonder where we should start...(pause)? How about if we all say where we are from?" 
This statement is one utterance. The type of speech is a question because the end of the utterance is in the form of a question.

SPEAKER 1: Well, I wonder where we should start...(pause)? How about if we all say where we are from?"

SPEAKER 2: “Okay, I'll go. I'm from Springfield, born and raised."

This would be scored as two utterances because one person spoke and then another. The first is a question and the second is a statement.

\section{What if the utterance is garbled such that no object can be discerned?}

Sometimes an utterance is too muffled or quiet to be heard. If no one responds to such an utterance, consider the utterance to be unsuccessful and do not code it. However, if someone does respond, even if the response is non-verbal (e.g., laughter at a whispered joke), attempt to code as many categories for the utterance as possible. It may be helpful to use others' responses as clues and to make a best educated guess about the nature of what was said. In the extremely rare case that a guess is impossible, use the other categories for type of speech.

\section{What if the "object" is implied or is not necessary to an utterance?}

In some situations, the object is implied by context, such as a previous statement or a shared understanding (e.g., "Uh huh..."). In other utterances, it is simply not necessary to discern the meaning of the utterance (e.g., "What?"). In these cases, code the utterance as if it is a completed verbal statement. Furthermore, the rule applies even if part of the statement meets these criteria (e.g., "Yea, don't talk..." is codable because the "Yea" could stand on its own). If the object is necessary for meaning, however, and it is not stated, due to a trail off in speech or an interruption, do not code the statement - for example: "Well don't..." or "I think we...".

\section{What about talk-overs?}

Talk-overs occur frequently. A talk-over is when two or more speakers are talking simultaneously. In these cases, only utterances that are sufficiently completed are scored. Again, this means that a) the subject and object are both present (or not necessary for meaning) or b) the statement elicits a response (verbal or non-verbal) from another group member. The overall goal is to code the utterances that most successfully enter the group's perceptual field. Similarly, the goal is to ignore fragmented or ignored statements, just as the group members have ignored them.

In the case of competitive talk-overs, we want the statement that continues to completion (subject and object) and/or elicits a response from another group member. Verbal comments that do not survive the talk-over are not coded (e.g., "But...", "I think we should...", "What does it...").

Example 1: 
(simultaneous speech)

SPEAKER 1: Start - We should try to come up with a lot of...

SPEAKER 2: $\quad$ Start - Why don't we write down all the suggestions.

In this case, only the second utterance would be coded because only the subject ("We") is present in the first statement. However, if someone were to subsequently respond to this first statement, you would need to go back and code it.

Example 2:

SPEAKER 1: Start - We should try to come up with a lot of ideas...

SPEAKER 2: Start - Why don't we write down all the

suggestions.

Both utterances would be coded because the first statement contains both a subject $(\mathrm{We})$ and a object (ideas).

\section{Partial overlaps?}

There are three types of talk-overs, depending on their temporal nature. In a partial overlap, cases where there is a temporal order to the talk-over, record each as a separate utterance in the order in which they began. For example, if the majority of a first statement is made, the next speaker overlaps with the end of this utterance and the overlap is completed, code both utterances in the order in which they occurred. Furthermore, if one speaker in the talk-over hesitates to let the other finish before he finishes, code them in the order in which they are completed. The example immediately above is a partial overlap.

\section{Full overlaps?}

A full overlap occurs when one statement begins and ends completely within the course of a previous statement. Speaker 1 starts talking, Speaker 2 starts and finishes, and then Speaker 1 finishes. It is like the second statement is sandwiched completely within the first, and is, thus, fully overlapped. Again, the overlapping statement must count as an utterance based on the criteria above if it is to be scored. Softly spoken, fully overlapped, think-out-loud types of verbal agreements are not counted unless of course they elicit a response.

Often these statements will occur in the form of support or agreement, such as "Uh huh" that is fully overlapped and supporting another's ideas as spoken. In these cases, assume that this type of statement is influencing the person to continue talking. Count the overlap as three separate utterances made by two different speakers. First, code the verbiage of the first speaker before the interruption, next code the sandwiched statement by the second speaker, and third code the end of the first person's statement as it was completed. Only the second statement is coded as a talk-over (see below). Often, the first verbiage will not stand alone as an utterance (having both a subject and object). Code it anyway, based on the content of the statement as a whole. In 
most situations, the response modes will remain the same (see Relational Communication, code B for specific coding instructions for full overlaps).

\section{Perfect overlaps?}

In rare cases, two or more utterances will begin at exactly the same time. Only code the dominant utterance whenever possible. In addition, the dominant utterance should not be coded as a talk-over in these situations. If both utterances are completed or elicit responses, code the one that is completed first as the first utterance and the other as the second. If they are completed at the same time, code the one that elicits a response first as the first utterance and the next one as the second.

\section{What if more than two people are talking concurrently?}

If several $(>2)$ people talk simultaneously, only code the dominant utterances (the one that emerges from the mess), even if one or more of the others is a complete sentence. In this case the dominant utterances are defined as the ones that elicit responses from other members (including non-verbals) or that emerge with relative clarity into moments of relative silence.

If the dominant utterance is the utterance that was started first, do not code it as a talk-over (see Relational Communication, code A). If it was not the first verbiage, do code it as a talk-over but code the target as a zero (see below).

If none of the utterances in the talk-over emerges as dominant (eliciting a response), do not code any of it; for example if they notice they are talking over one another, stop, and backtrack. Another common example is when a vote is called for and all the members say, "I." Never code these types of group votes. 


\section{Relational Coding: Control, Conflict, and Closeness \\ [Adapted from Erickson and Rogers (1973)*]}

Each utterance should be observed on video several times, first to code speaker (is it an utterance? And if so, who said it?) and then each relational code. In the case of talk-overs it may be necessary to rewind and replay the tape several times to determine the number and order of utterances to code. Finally, when the coding is completed, the entire tape should be reviewed to double check whether any utterances have been missed, any unsuccessful interruptions have been included, or any relational scores are incorrect.

Affect (1-7): Affect may be inferred through non-verbal cues (i.e., facial expression, body language, changes in pitch, volume, etc.) or through verbal content (i.e., "What?" [confused], "I already asked you that." [frustrated]. "That's funny." [happy]).

Be careful using verbal content alone. For example, not all questions should be coded as confusion. Verbal content is best used alone when a neighboring statement by the same person contains some non-verbal cue. For example, if a challenge is stated simply as a "what?" and subsequently contains frustrated cues, both statements may be codes as frustrated. The coder must use some degree of subjective judgment in deciding when the frustration likely began. The important thing to note is that other information, both before and after the utterance may be used to provide information about affect.

Only one affect code may be assigned. If the speaker appears to be in a mixed emotional state, the rater should judge which emotion appears to be most strongly expressed or that is present further toward the end of the statement. For example, if a member begins with a frustrated challenge to another member but then becomes embarrassed because he has accidentally made a mistake, code embarrassed.

As a rule of thumb, if you can site any specific evidence from any of the categories above (non-verbal or verbal content) to support your judgment, your judgment is probably correct. The goal is to capture any affect that is present, even if this results in occasional false positives. If you can't support your judgment with any concrete evidence, record a 1 for neutral. The emotional categories are listed below. Record one number next to the speaker code for each utterance.

$\mathbf{1}=$ neutral/calm $\mathbf{2}=$ happy/enthusiastic $\mathbf{3}=$ sad/disappointed $\mathbf{4}=$ frightened-anxious/shockedembarrassed $\mathbf{5}=$ angry/frustrated/defensive $\mathbf{6}=$ confused $^{* *} \mathbf{7}=$ other (record emotion)

*Some portions of the coding scheme above contain direct quotes from Ericson and Rogers (1973) that are not cited properly. Quotation marks were not included in these instances to make the scheme easier for coders to read.

\footnotetext{
**Confusion as a part of the brainstorming process in problem-solving discussions is not coded. For example, if the members are simply brainstorming for ideas or if a response is queried by another member because it was unclear. However, clear confusion about some specific element of the task itself (e.g. What are we supposed to do? Or: What is that word I'm trying to think of?) is coded as confusion.
} 
Talk-over (3) and target (n): A talk-over is an interruptive manner of coming into the conversation that overlaps another statement. This category would include all dominant utterances (see speaker section above). Obviously one would only assign codes to those utterances that were assigned a speaker code based on the criteria above.

The target of the talk-over is the speaker who was making the statement that was interrupted. Record the target's number to the right of the talk over code (i.e., 3-2). The target is always recorded, even if the utterance was not, specifically if the interrupted verbiage was insufficient to receive a speaker code (see speaker section above).

Again, if a statement emerges from background chatter ( $>2$ simultaneous utterances) and began first, do not code it as a talk-over. Conversely, if a statement emerges from background chatter but did not begin first, do code it as a talk-over, with the target as the clearest (next earliest, loudest and most complete) statement made by another speaker. If this target can not be discerned, leave the target space blank (i.e., 3-_) indicating an interruption with no target.

Sometimes, there will be a mild overlap between speakers at the end of a statement. These are not meant to be coded as talk-overs. To code a talk-over, there must be a clear interruption. Specifically, if one-half of the syllables of the final word of a sentence have been uttered, the subsequent statement is not a talk-over.

Example:

SPEAKER 1: We should try to come up with a lot of ideas so that... SPEAKER 2: $\quad$ Why don't we write down all the ideas and then decide.

Code the second utterance as a talk-over and record the first speaker as the target of that talk over.

Control (record 0 or 1): Record a " 1 " for control for answers, instructions, or topic changes, each of which will be described in turn. There will be no target for utterances scored as Control.

Answers are responses that have substance and/or commitment and that do not convey either support or non-support for the previous statement. A noncommittal response such as "I don't know" to a question is coded as a support/extension (see below), while a definitive response such as "It was July $6^{\text {th" }}$ is coded as an answer since the two types of responses have different control-defining natures.

Basic informative statements are also coded as answers, even if it not sequentially following a question so long as they do not qualify as support/extensions or non-support/disconfirmations (see below).

Instructions are demands, which may be accompanied by a qualification and clarification. For example, "Give me that." is an instruction. In addition, non-hostile direct questions (questions that query specific information as opposed to just conveying uncertainty) are coded as Control because they imply that an individual, or the group as a whole, should provide 
an answer unless they are non-support/disconfirmations (see below). A final key distinction must be made for instructions that demand a change in a specific group member's behavior. These instances are coded as non-support/disconfirmations, because they imply a lack of support for the current behavior of the targeted group member. The lack of support may either be stated (e.g., Stop snapping your gum like that."'), or may be inferred through context or negative affect (e.g.,"[frustration] Give me that!"). It may also come in the form of a question (e.g., "Why do you always to that'?"). Demands for change from the group as a whole are instructions, coded as Control (i.e., We should try to get focused here").

A topic change is the initiation of a new idea without ignoring the previous statement, for example, providing a new topic of conversation when the prior topic has been exhausted. Other examples include distraction from the task at hand or reading the next stimulus-question in structured discussions.

Conflict (score 1-5) and target (n): Conflict is based on non-supportive or disconfirming responses, conveying disagreement, rejection, and challenges. "That wouldn't work," is a clear example of a non-support.

A disconfirmation is used to indicate a message or response by one individual that ignores or bypasses the message of another individual. For example, "Let's talk about hobbies" followed by: "We should talk about what jobs we do." is considered a disconfirmation.

In the case of structured problem-solving discussions involving recorded answers, do not code the next idea as Conflict if the recording member has begun to write the answer down. In this instance the recording of the answer serves as a signal to move on to other ideas and the statement should be coded as Control because it represents a topic-change. A more difficult example of a disconfirming Conflict is when a member tries to significantly modify the previous participant's answer. An answer is considered significantly modified if a key element of the answer has been changed. Most clearly, if a different answer altogether is given without regard any regard to the first answer, code Conflict.

In less obvious examples, the modification may be related to the first statement, such as: Speaker 1: "Aerobic exercise is good." Speaker 2: "Spinning classes." In these cases, the significance of the modification must be inferred by the lack of use of qualifiers (e.g., and, or), by the degree to which the content has been altered, and by the degree to which the tone and/or timing connotes disagreement or disregard for the previous statement. The benchmark for a significant change in content exists when content goes from general to specific. A move from general to specific is considered to be a minimally significant modification because it discounts other specific instances suggested by the first person. The example immediately above illustrates this point. However, moving from specific to general (from (spinning to aerobic exercise) would not be considered to be significant because it includes the specific instance listed by the previous member. Again, if the modification is not a significant modification, code as a supportlextension.

Finally, teasing, even if it is good-natured, is Conflict. The only exception to this rule is if a good-natured teasing sequence is broken by the target's joining in with a genuine non-defensive 
manner. In these cases, subsequent good humor that is shared among the participants is coded as Closeness.

The target of the Conflict is the speaker to whom the statement applies. The target will usually apply to the member who made the preceding statement. If it applies to a different member or group of members in the case of a coalition (see below), write that member's number in the space above the relational code. The target is always recorded, even if his utterance was not, specifically if the target's response did not qualify as a codable utterance (see What is an utterance section above.). Specifically, if the subject has been stated in a talked-over statement, code the talk-over as Conflict, even though the first statement is not coded. The only exception to this rule is when it is clear that a talk-over is assisting the previous member in completing the intended statement, which would be coded as Closeness (see below).

Scoring the Conflict: All Conflict scores have target(s). For example, if speaker 1 disconfirms the statement of speaker 2, conflict was scored from speaker 1 to speaker 2 . Keep in mind that direction is important. Only score conflict in this case for 1-2, in the appropriate order. Conflict in the direction 2-1 would only be scored if there is some subsequent retaliation by speaker 1 directed at speaker 2. Thus, the total conflict score for relationship 1-2 will most likely differ from that of 2-1.

Once Conflict is identified, one must determine its strength. The strengths will range from one to five. The following are the rules for scoring conflict:

1) A score of one represents a challenge to a specific behavior or task-related idea. These are simple disconfirmations or non-supports and should be the most common conflict statements. "I don't think we should write that down?" would be a level one conflict.

2) A score of two represents a more general challenge to the person, the person's beliefs, values or a pattern of behavior. Thus, any disagreement with a value statement, belief, personal characteristic or behavior that has occurred more than one time would represent a level two conflict. This means that decisions about conflict levels require the coder to examine the previous statement. For example, if participant 1 says, "I believe in abortion rights." and participant 2 disagrees with or disconfirms this statement, a score of two should be assigned. Within coalitions (see below), personal criticisms (i.e., "you don't understand the issues involved.") should only be applied to the person toward whom they are aimed, not to every other member who is allied with that member.

3) If a statement is identified as Conflict and has a code for angry/frustrated/defensive from the affect list above, one point is added to the conflict score for that utterance. Thus, a challenge to an idea with frustration is scored as a two instead of a one. Similarly, a challenge to a person, the person's general beliefs or values with anger/frustration/defensiveness is scored as a three instead of a two.

Likewise, if the conflicting statement is also a talk-over, it earns an extra point. Thus, a challenge to an idea that is also a talk-over is scored as a two instead of a one. Similarly, a challenge to a person, the person's general beliefs or values that is also a talk over is scored as a 
three instead of a two. Finally, if the statement challenges a belief, has anger/frustration/defensiveness and is a talk-over, it would be scored as a 4 .

4) Conflicting statements scored as four, must involve an implicit or explicit physical threat. "Shut up!" and similar person-centered verbal attacks are defined as the minimum intensity. However, happy/enthusiastic affect negates a level-four threat. For example, a happy/enthusiastic "Shut up." would be scored as a level one conflict.

5) Threats that are also talk-overs are scored as level 5 conflicts.

Closeness (score from 1-5) and target (n): The Closeness category refers to supportive and extending statements. They may involve giving and seeking agreement, assistance, acceptance, and approval for the previous verbal statement or some non-verbal behavior of another group member (i.e., thanking someone for a piece of gum). A clear example of a support is: Yes, that's a good idea. Or more simply: Yea...

More difficult, examples of support include: 1) Following a direction (except answers to direct questions which are coded as Control), or 2) Repeating someone else's answer to a question. Extensions are messages that continue the flow or theme of the preceding message and convey approval. Included under this category is a noncommittal response to a question (e.g., I don't know.).

\section{Examples:}

SPEAKER 1: I don't like classes with a lot of exams.

SPEAKER 2: And too many papers to do can be a drag too.

Extensions may be hard to differentiate from similar ideas presented with the intent to usurp or one-up the previous member's statement by changing it slightly and then taking credit. Helpful clues for true Closeness utterances include: using and, a conditional or, or agreeing before the related idea is stated (e.g., SPEAKER 1: Apples are great. SPEAKER 2: Yea, especially green apples, is Closeness. On the other hand, SPEAKER 1: Apples are great fruit. SPEAKER 2: Green apples, is Conflict as described above).

When affect is conveyed and continued by another member, Closeness should be coded for that statement. This is common in coalition situations (see below), such as when a member conveys shared frustration with another against a third member. Another example of an affective Closeness statement is the continuation of happy/enthusiastic affect by continuing a joking sequence.

The target of the Closeness is the speaker(s) to whom the statement applies. The target will usually apply to the member who made the preceding statement. If it applies to a different member or to multiple members in the case of coalitions, write those members numbers to the right of the closeness score (i.e., 1-2, 3...). The target is always recorded, even if the original utterance was not, specifically if the utterance did not qualify as a dominant utterance (see speaker section above). 
Scoring the Closeness: The closeness scores mirror those of conflict. A closeness code was assigned to each utterance identified within the speaker coding criteria above. If there is no closeness expressed within the verbal statement, assign a zero.

Any utterance that is a support/extension is coded as a closeness utterance for that speaker in the direction of the targeted speaker. For example, if speaker 1 extends or supports the statement of speaker 2, closeness was scored between 1 and 2. Keep in mind, however, that direction is important. Only score closeness in this case for 1-2, in the appropriate order. Closeness in the direction 2-1 would only be scored if there is some subsequent retaliation by speaker 1 directed at speaker 2. Thus, the total closeness score for relationship 1-2 will most likely differ from that of $2-1$.

Once a supportive utterance is identified, one must discern the strength of the agreeing statement. The strengths will range from one to five. The following are the rules for scoring closeness:

1) A score of one represents a support for a specific, task-related idea. These are simple supportive utterances that are directed at an idea and should be the most common closeness statements. "Yea, we should write that down?" would be a level-one Closeness utterance.

2) A score of two represents more general support for the person, the person's beliefs or values. Thus, any agreement with a value statement of belief would represent a level two closeness. This means that decisions about closeness levels require the coder to examine the previous statement. For example, if participant 1 says "I believe in abortion rights." and participant 2 agrees, a score of two should be assigned.

3) If a statement is identified as conveying closeness (again any supportive or extending statement) and has a code for affect from the affect scheme above, one point is added to the closeness score for that utterance. Thus, support of an idea with happiness is scored as a two instead of a one. Similarly, a support of a person, the person's general beliefs or values with happiness is scored as a three instead of a two. Finally, in a coalition situation (see below) anger would result in the addition of a point for closeness.

Likewise, if the closeness statement is also a talk-over, it earns an extra point. Thus, support of an idea that is also a talk-over is scored as a two instead of a one. Similarly, support of a person, the person's general beliefs or values that is also a talk-over is scored as a three instead of a two. Finally, if the statement supports a belief, has happy/enthusiastic affect and is a talk-over, it would be scored as a 4 .

4) Closeness statements scored as four, must involve defense from an implicit or explicit physical threat. Thus, level-four support can only emerge immediately following a level four conflict. In these situations the closeness usually will not be applied to the speaker of the previous utterance because this utterance will involve a verbal threat to another group member. Thus, the coder must discern whom the speaker is defending and apply a score of four to that relationship. Because this defense necessarily involves a conflict with the previous statement (the verbal attacker), a conflict score should be scored as well. 
5) Support/extensions from a threat that are also talk-overs are scored as level-5 closeness.

\section{What about conflict and closeness in split-code (coalition) situations?}

The rules for adding points are simply mirrored in split response mode situations (coalitions). For example, if a member enthusiastically agrees with a member in a conflict or happily jokes along with teasing, both the closeness and conflict scores would get an additional point. The same is true for additional points due to talk-overs or personal attacks (so long as the personal attack precedes the current response). Basically all split-code scores (Conflict with Closeness) should be identical in conflict and closeness in nearly every situation. The only exception is when a specific personal attack is levied as is described above. In the event of a personal attack during a coalition, the bonus point for personal criticism is only applied to the specific target of that criticism.

What if the relational code applies to the statements of two or more individuals, such as disconfirming one member while supporting another?

Occasionally, there may be a battle between two different trains of ideas, usually in the form of a coalition, where members take sides in a conflict (e.g., "She could do aerobics." Followed by, "She could join a spinning class." Followed by, "Yea, aerobics is good." Followed by, "...they have spinning at Balleys."). In these situations, code both of the split-codes and all of the targets for each statement. In the example above, all but the first statement would be coded as Conflict targeting the previous statements. In addition, the last two utterances would each be coded as Closeness, targeting the statement two utterances back. Once a member becomes involved in the coalition, either by supporting and/or non-supporting, they continue to be involved until the contested topic (aerobics or spinning) dissipates, either by capitulation or a topic change. For example, if a fifth member said "Yea" to one of the ideas in the conflict above, he or she would remain as a target for all related subsequent statements. In this way, a conflict may grow larger as more and more members are pulled in along the way.

Each combination of response modes is possible, although splits (Conflict and Closeness) are the most common. For example, a double support may occur when a third member tries to settle a dispute by synthesizing two ideas (e.g., "She could do aerobics." "She could join a spinning class." Followed by: "I think 24-hour Fitness has both classes."). Similarly, double conflicts may occur, the most frequent is when a coalition is triangulated, with one member against two others.

It is important to differentiate the ideological splits (coalitions) above from multiple trains of conversation that occur simultaneously without conflict. In a multiple-train situation, the group's attention is split, focusing on two or more tasks; while in a coalition two or more factions are battling for the focus of the group's attention. The situation is analogous to an individual who tries to do multiple tasks; listening to the radio while driving is like a multiple train while watching T.V. would cause dissonance or conflict. A common example of a multiple train is when two or more members are discussing a topic and another member asks a specific unrelated question of another member, such as, "Can I see that?" In these non-conflicting splits do not code Conflict unless there are clear talk-overs. 
Other (4): Other is a residual category for the extremely rare case in which a response is not classifiable based on the three categories above.

What priority is given in coding?

The following is the order of priority (the order to follow in deciding codes) for the 3-C codes above:

\section{Closeness $>$ Conflict $>$ Control.}

Ask yourself: "Is it a support or extension?" If no, "is it a non-support or disconfirmation?" If it is neither of these, it is an answer/instruction/topic-change. 